\title{
Driving Performance Evaluation Using Bio-signals from the Prefrontal Lobe in the Driving Simulator
}

\author{
Younghyun Kim, Yongchul Kim \\ Department of Rehabilitation Science and Technology, Daegu University, Kyungsan, 712-714
}

\begin{abstract}
Objective: The aim of this study was to develop the assistive device for accelerator and brake pedals using bio-signals from the prefrontal lobe in the driving simulator and evaluate its performance. Background: There is lack of assistive devices for the driving in peoples with disabilities in Korea. However, if bio-signals and/or brain waves are used at driving a car, the people with serious physical limitations can improve their community mobility. Method: 15 subjects with driver's license participated in this study for experiment of driving performance evaluation in the simulator. Each subject drove the simulator the same course 10 times in three separated groups which use different interface controllers to accelerate and brake: (1) conventional pedal group, (2) joystick group and (3) bio-signal group(horizontal quick glance of the eyes and clench teeth). All experiments were recorded and the driving performances were evaluated by three inspectors. Results: Average score of bio-signal group for the driving in the simulator was increased 3\% compared with the pedal group and was increased $9 \%$ compared with the joystick group $(p<0.01)$. The subjects using bio-signals was decreased $44 \%$ in number of deduction compared with others because the device had the built-in modified cruise control. Conclusion: The assistive device for accelerator and brake pedals using bio-signals showed significantly better performance than using general pedal and a joystick interface $(p<0.01)$. Application: This study can be used to design adaptive vehicle for driving in people with disabilities.
\end{abstract}

Keywords: Bio-signal, EEG sensor, Driving simulator, Human machine interface(HMI)

\section{Introduction}

운전면허를 취득한 인구수는 나날이 증가하여 현재 2 천 5 백만이 넘는 인구가 면허를 보유하고 있다. 전체 인구수 중 20세 이상 70 세 미만은 약 3천 2백만 명이며(Statics Korea, 2009), 이를 토대로 운전면허 보유율을 계산하면 약 $78 \%$ 가 된다.

국민의 대다수가 운전면허를 보유하고 있거나 취득을 희 망하고 있다. 또한 원한다면 누구라도 적법한 절차를 통해 면허를 취득할 수 있는 기회를 가진다. 하지만 일부 장애인 등은 그 장애의 특성으로 인해 차량 운전을 시도조차 하지
못하는 실정이다. 약 240만 명의 등록 장애인(Employment Development Institute, 2010) 가운데 운전면허를 소지 한 장애인수는 약 12만 명이다(Road Traffic Authority, 2009). 이는 동년대비 국민 전체 운전면허 취득자수에 비하 면 약 $0.5 \%$ 에 불과하다. 또한, 20 세 이상 70 세 미만의 장애 인구수 대비는 약 $7.4 \%$ 에 해당하는 사람만 운전면허를 보 유하고 있다. 비장애인과 비교하면 약 $10 \%$ 수준의 운전면 허 소지율을 보이고 있다.

2008년 6월에 개정된 신체 상태에 따라 받을 수 있는 운 전면허 및 조건부과기준(도로교통법 제 54 조 제 2 항 및 61 조 관련 별표 20)에는 양팔, 양다리, 한쪽 팔, 한쪽 다리의 신체 상태에 따라 자동변속기, 핸드컨트롤러, 왼쪽 가속 페달 등

Corresponding Author: Yongchul Kim. Department of Rehabilitation Science and Technology, Daegu University, Kyungsan, $712-714$.

Mobile: 010-9686-4240, E-mail: nakim@daegu.ac.kr

Copyright@2012 by Ergonomics Society of Korea(pISSN:1229-1684 eISSN:2093-8462). All right reserved.

(c) This is an open-access article distributed under the terms of the Creative Commons Attribution Non-Commercial License(http://creativecommons.org/licenses/by-nc/3.0/), which permits unrestricted non-commercial use, distribution, and reproduction in any medium, provided the original work is properly cited. 
본인의 신체장애 정도에 적합하게 제작 승인된 자동차로 명 시되어 있다.

미국과 일본 등의 선진국에서는, 조이스틱과 소형 핸들을 비롯한 다양한 운전보조장치를 사용하여 국내 보다 다양 한 장애 유형의 대상자가 운전을 할 수 있도록 하고 있다 (Pellerito Jr., J.M., 2006; Tsutomu, 2004). 반면 국내의 경우 한쪽 팔과 양하지에 손상을 입은 장애인 그리고 양하지 와 양상지에 손상을 입은 중증 장애인의 경우에 적합한 운전 보조장치가 없는 실정이다. 장애인 운전면허의 취득을 위하 여 제도 및 지원 체계를 구축해야 하며, 아울러 각 장애인들 의 요구와 장애특성에 부합하는 다양한 운전보조장치의 개 발이 필요하다(Lee et al., 2004).

2005년도 한국보건사회 연구원 통계자료에 의하면 지체 장애인의 장애 부위별 분포를 살펴 보면 운전면허 취득 조건 에 해당하는 대상자가 지체 장애인 중에 약 $71.3 \%$ 에 해당 하며, 특히 양하지를 사용하지 못하거나 또는 상지 한쪽과 양하지를 제한적으로 사용하더라도 인지와 지각 기능에 이 상이 없으면 보다 용이하게 운전보조장치를 통하여 자신의 생각과 판단에 따라 자가 운전을 할 수 있을 것이다. 인간의 몸은 대뇌에서 나오는 신경 신호에 따라 움직인다. 신경 신 호를 검출하고 이를 통해 운전을 할 수 있게 된다면, 보다 중증인 지체 장애인들도 자가 운전을 할 수 있게 되어 그들 의 이동권과 독립생활을 확보하고 삶의 질을 높일 수 있을 것이다.

생체 신호나 뇌파 신호를 이용하여 전동 휠체어를 제어하 는 연구(Oonishi et al., 2010; Kim et al., 2006; Barea et al., 2002; Iturrate et al., 2009; Galan et al., 2008; Vanacker et al., 2007; Rebsamen et al., 2007; Tanaka et al., 2005) 는 많이 있지만, 그 동안 생체 신호를 이용한 자동차관련 연 구의 대부분은 운전자의 부주의, 피로, 졸음 운전 등과 같이 사고 예방을 위한 운전자의 안전과 관련된 연구들이었다 (Park et al., 2010; Eoh et al., 2005; Zhao et al., 2012). 생체 신호를 이용한 차량의 제어와 관련해서는 일정한 주행 속도에서 조향 제어를 위한 연구(Jaime et al., 2011)와 조향 및 주행 속도 제어에 관한 연구(Kwak et al., 2008; Zhao et al., 2009)가 최근에 이루어지고 있다. 생체 신호를 이용하여 차량의 조향각을 제어하는 방법은 아직까지 손으 로 운전하는 것에 비하여 많은 오차가 발생한다(Jaime et al., 2011). 특히, 자동차의 경우 편리한 만큼 위험한 수단으 로 이를 제어하기 위해서는 무엇보다 정확성과 안전성이 요 구되기 때문에 본 연구에서는 손으로 조향 장치를 조종하고 생체 신호를 이용하여 가감속 장치 및 제동 장치를 제어하고 자 한다.

따라서, 본 연구에서는 전전두엽 뇌파 측정 시 혼입되어 들어오는 생체 신호 중 안구의 움직임과 이물기를 통한 저작
근 신호를 이용하여 자동차의 가속 페달과 제동 페달을 제어 할 수 있는 액츄에이터를 개발하고, 기존의 페달 방식과 조 이스틱 방식과 운전 성능을 비교 분석하였다.

\section{Materials and Methods}

\subsection{Subjects}

본 연구의 실험은 지체 장애인 중에서 양하지 장애 또는 상지 한쪽과 양하지 장애를 가진 사람들을 위한 생체 신호를 이용한 가감속 및 제동 장치의 성능을 평가하는 것이 목적이 다. 환경적 제약으로 운전을 하기 어려운 장애인이 개발된 장비를 사용하기 전에 일차적으로 장비 자체에 대한 검증이 이루어져야 하며, 고려 대상자가 모두 양쪽 하지 장애를 가 진 지체 장애인이기 때문에 본 연구에서는 생체 신호를 이 용한 그룹의 경우 비장애인 실험대상자에게 양하지를 사용 하지 않도록 제한하여 실험을 수행하였다.

개발된 생체 신호를 이용한 가감속 장치의 성능 평가와 비 교를 위한 대조군으로 3 개의 그룹을 편성하였다. 가감속을 제어하는 방법에 따라 개발된 생체 신호를 이용하는 그룹, 조이스틱을 이용하는 그룹, 일반 페달을 이용하는 그룹의 3 개의 그룹으로 나누고 각 그룹의 인원수는 5 명으로 총 15 명 이 실험에 참여하였다. 그룹간 그리고 개인간 운전수행능력 은 차이가 있을 수 있으며 실험 결과에 영향을 미칠 수 있

Table 1. Characteristics of subjects

\begin{tabular}{c|c|c|c|c}
\hline \multicolumn{2}{c|}{ Driving interface } & Gender & $\begin{array}{c}\text { License issued } \\
\text { date }\end{array}$ & $\begin{array}{c}\text { Driving career } \\
\text { (months) }\end{array}$ \\
\hline \multirow{4}{*}{$\begin{array}{c}\text { Pedal } \\
\text { group }\end{array}$} & $\mathrm{A}$ & $\mathrm{F}$ & 2007.12 & 6 \\
\cline { 2 - 5 } & $\mathrm{B}$ & $\mathrm{M}$ & 2004.12 & 12 \\
\cline { 2 - 5 } & $\mathrm{C}$ & $\mathrm{F}$ & 2003.03 & 1 \\
\cline { 2 - 5 } & $\mathrm{D}$ & $\mathrm{M}$ & 2005.05 & 12 \\
\cline { 2 - 5 } & $\mathrm{E}$ & $\mathrm{F}$ & 2009.08 & 5 \\
\hline \multirow{4}{*}{$\begin{array}{c}\text { Joystick } \\
\text { group }\end{array}$} & $\mathrm{F}$ & $\mathrm{F}$ & 2009.04 & 5 \\
\cline { 2 - 5 } & $\mathrm{G}$ & $\mathrm{M}$ & 2006.07 & 12 \\
\cline { 2 - 5 } & $\mathrm{H}$ & $\mathrm{M}$ & 2006.03 & 3 \\
\cline { 2 - 5 } & $\mathrm{I}$ & $\mathrm{M}$ & 2008.12 & 11 \\
\cline { 2 - 5 } & $\mathrm{J}$ & $\mathrm{F}$ & 2009.01 & 10 \\
\hline \multirow{4}{*}{$\begin{array}{c}\text { Bio-signal } \\
\text { group }\end{array}$} & $\mathrm{K}$ & $\mathrm{F}$ & 2007.05 & 6 \\
\cline { 2 - 5 } & $\mathrm{L}$ & $\mathrm{M}$ & 2004.02 & 12 \\
\cline { 2 - 5 } & $\mathrm{M}$ & $\mathrm{M}$ & 2007.08 & 1 \\
\cline { 2 - 5 } & $\mathrm{N}$ & $\mathrm{M}$ & 2006.01 & 6 \\
\cline { 2 - 5 } & $\mathrm{O}$ & $\mathrm{F}$ & 2007.02 & 1 \\
\hline
\end{tabular}


다. 그러므로 모든 실험대상자는 운전면허를 취득한지 6 개 월 이상으로 그 능력이 증명된 사람으로 제한하였다. 또한 최근 1 년 사이의 실제 운전경력과 남녀의 비율을 비슷하게 유지하였다. 실험대상자의 그룹 및 특성 현황은 Table 1 과 같다.

\subsection{Experimental setup}

생체 신호를 측정하기 위해서 MP150 System(Biopac systems, USA)의 뇌파(EEG) 측정용 전극캡(CAP100C) 을 사용하였다(Figure 1). 이것은 국제 협약에서 정한 1020 법을 바탕으로 일정한 간격으로 전체 대뇌를 포함하는 20 개의 전극이 부착되어 있다. 측정 앰프의 게인 값은 5,000 으로 설정하였다. 샘플링 주파수는 $200 \mathrm{~Hz}$ 로 하였으며, 뇌파 전극을 이용하여 눈흘김 신호를 추출하기 위해 버터워스 방 법의 3 차수로 $5 \mathrm{~Hz}$ 저역통과필터(low pass filter)를 적용하 였다. $5 \mathrm{~Hz}$ 이하의 $\mathrm{EEG}$ 신호는 델타파로 분류되며, 일반적 으로 깊은 수면 시 나타나는 파형이기 때문에 각성 상태에 서는 나타나지 않으며, 이때 눈 움직임 신호만 반영되어 나 타나게 된다(Figure 5). 눈을 움직이는 경우 주변의 사물을 관찰 하거나 눈을 깜박이는 신호와 구별하기 위해서 본 연구 에서는 눈을 기준값 이상의 힘을 주어서 좌우로 움직이는 신 호를 측정하였으며, 좌우측 2 개의 채널 신호의 차이를 계산 하여 운전자의 머리나 눈 깜박임과 같은 움직임과 관련된 외부 노이즈를 제거하였다,

운전 시뮬레이터에 추가되는 운전보조장치 중 하나로 가 감속 액츄에이터를 설계하는데 실제 차량에 적용하여도 개 조하는데 어려움이 없어야 한다. 따라서 가감속 액츄에이터 는 차량 내부 또는 시뮬레이터 내부에서 작동하지 않고 운전 석에서 겉으로 보이는 곳에 장착되고 작동될 수 있도록 하였 다. 본 연구에서 설계한 가감속 액츄에이터는 페달의 누르는 정도를 조절할 수 있도록 Ezi-Servo 모터와 모터 드라이 버 (FASTECH, Korea)를 사용하였다. 또한 생체 신호를 처

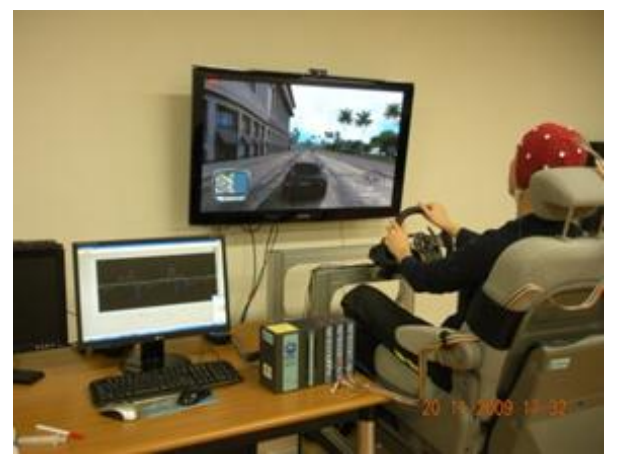

Figure 1. Experimental setup
리하여 모터를 작동시킬 수 있도록 하기 위하여 Labview 8.6 (National Instruments, USA) 프로그램과 모션카드 (NI PCI-7390)를 시뮬레이터용 PC에 설치하였다.

\subsection{Control algorithms}

다음 단계로 Labview 프로그램을 이용하여 2축 모터를 제어하여 가속 페달과 제동 페달을 제어할 수 있는 프로그램 을 제작하였다. 전극캡을 이용하여 1채널에는 10-20법의 $\mathrm{Fp} 1-\mathrm{F} 7$ 의 전극위치에서 신호를 받고, 2채널에는 Fp2-F8 의 전극위치에서 신호를 받는다. 원 신호(raw data)를 $5 \mathrm{~Hz}$ $\mathrm{LPF}$ 처리를 하여 눈흘김 신호를 판단한다. 오른쪽으로 눈을 흘기는 동작을 하면 가속제어모터가 시계방향 $(\mathrm{CW})$ 으로 작 동하여 시뮬레이터 차량의 속도가 증가하게 된다. 왼쪽으로 눈을 흘기는 동작을 하면 가속제어모터가 반시계방향 $(\mathrm{CCW})$ 으로 작동하여 속도가 감소하게 된다(Figure 2). 시뮬레이 터 차량의 속도를 증가시키기 위해서는, 가속제어모터는 1 도씩 시계방향으로 회전하며 시뮬레이터 차량의 모터를 약 $1,000 \mathrm{rpm}$ 씩 증가하게 한다. 눈흘김 동작을 수행하면 평지 에서 기준으로 한 번 수행 시마다 차량의 속도는 약 $10 \mathrm{~km}$ $/ \mathrm{h}$ 단위로 서서히 증가하게 되고 총 5 번의 가속을 하고, 속 도가 $45 \mathrm{~km} / \mathrm{h}$ 를 넘어가는 순간 기어가 1 단에서 2 단으로 변 속된다. 모터의 위치가 같을 때, 기어 2단일 때 차량의 속도 는 약 $40 \mathrm{~km} / \mathrm{h}, 50 \mathrm{~km} / \mathrm{h}, 60 \mathrm{~km} / \mathrm{h}, 70 \mathrm{~km} / \mathrm{h}$ 이다. 마찬가지로 총 5 회 가속 동작을 하여, 속도가 $80 \mathrm{~km} / \mathrm{h}$ 를 넘어가는 순간 기어가 2단에서 3 단으로 변속된다. 가령 최초 정지 상태에 서 오른쪽으로 눈흘김을 5 번 수행하면 속도는 $80 \mathrm{~km} / \mathrm{h}$ 까 지 천천히 증가하게 된다. 시뮬레이터 차량의 속도를 줄이기 위해서는 왼쪽 눈 흘김 동작을 수행하게 되며, 가속제어모터 는 1 도씩 반시계방향으로 회전하게 되며 한 번 수행마다 $10 \mathrm{~km} / \mathrm{h}$ 단위로 서서히 감속하게 된다. 기어 2 단인 $80 \mathrm{~km} / \mathrm{h}$ 상태에서 왼쪽으로 눈흘김을 한 번 수행하면 차량의 속도는 $70 \mathrm{~km} / \mathrm{h}$ 를 유지하게 된다.
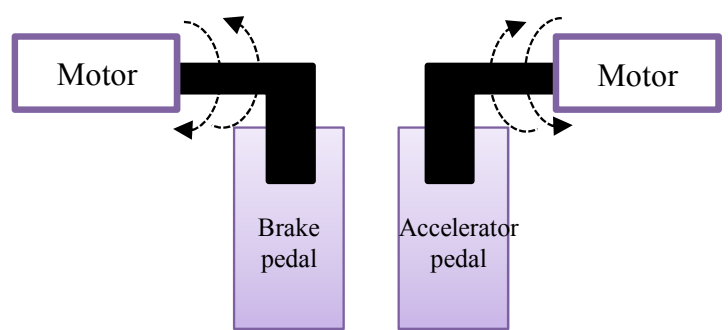

Figure 2. Actuator system for accelerator and brake pedal

원 신호는 한쪽에서 $5 \mathrm{~Hz} \mathrm{LPF}$ 를 하여 눈흘김 동작을 구별 
할 수 있도록 하는 동시에 다른 한 쪽에서는 제동을 위한 이물기 신호를 구별하기 위하여 $50 \mathrm{~Hz} \mathrm{HPF}$ 를 한다. 일반적 으로 유용한 근전도 신호는 $15 \mathrm{~Hz}$ 에서 $500 \mathrm{~Hz}$ 까지 나타난다. 근전도 신호에 해당하는 이물기 신호를 $50 \mathrm{~Hz} \mathrm{HPF}$ 하는 이 유는 각성 시 나타나는 뇌파의 베타파를 차단하기 위함이 다. 이물기 신호와 눈흘김 신호가 동시에 참이 되는 경우에 는 이물기 신호가 우선하여 제동제어모터가 작동하게 된다 (Figure 3).

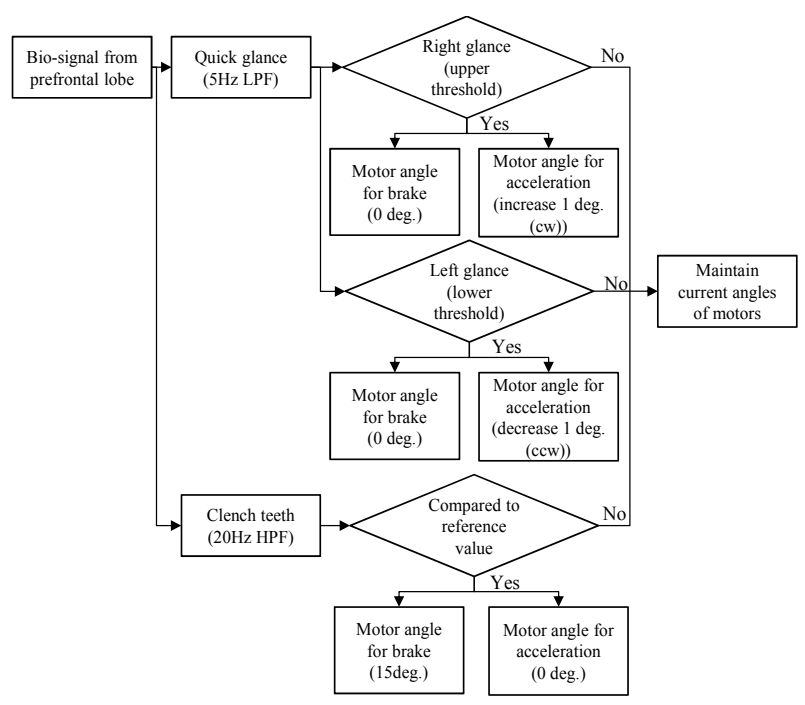

Figure 3. Control algorithms

\subsection{Experimental procedure}

본 연구의 실험대상자들이 운전면허를 보유하고 있으나, 시뮬레이터의 특성상 그리고 운전보조장치의 사용여부에 따 라 적응 기간이 필요하다. 그 기간은 개인마다 차이가 있을 수 있으므로 실험 결과에 학습 곡선을 고려하여야 한다. 실 험은 5 일간 실시하고 하루에 2회 지정된 코스를 완주하는 것으로 한다. 조용한 실험환경을 조성하고, 실험자의 불필요 한 움직임을 통제하였다.

코스의 선정은 도로교통법을 참고하여 프로그램상의 (Tested drive unlimited, USA) 하와이 시내지역으로 하였 다(Figure 4). 코스의 총 거리는 $5.4 \mathrm{~km}$ 이다. 교차로가 8곳 있고 그 중 신호등이 있는 곳은 3 군데이다. 비보호 교차로가 5 개 있다. 또한 코스 중에 좌회전을 4 번 하게 되어 있고, 우회전을 2 번 하게 되어 있다. 코스가 실제 국내 도로와는 차이가 있지만 운전자의 도로 주행 성능 평가를 주 목적으로 하였기 때문에 모든 대상자에게 동일한 낮선 환경에서의 도 로 주행 성능 평가를 수행하였다.

모든 주행 시험은 시뮬레이터 화면을 녹화하여 시험 후에
도 재확인을 할 수 있도록 하였다. 3 인으로 구성된 평가자는 사전에 시뮬레이터 주행 시험의 시험항목·채점기준 및 합 격기준을 숙지한 후, 녹화된 화면을 보며 채점을 하였다.

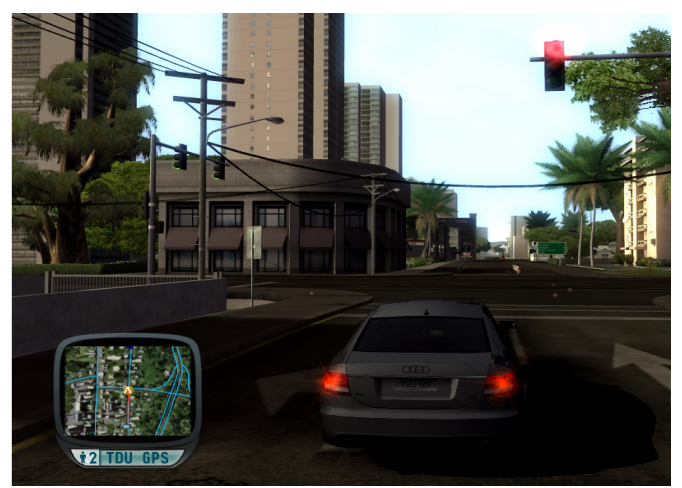

Figure 4. Driving map using test drive unlimited

\subsection{Data analysis}

운전 시뮬레이터에서 가감속 제어 장치의 특성에 따른 운 전 성능을 분석하기 위하여 읜도우용 Minitab 15 통계 프로 그램을 이용하였다. 가감속 장치를 제어하는 방법에 따라 본 연구에서 개발된 생체 신호를 이용하는 그룹, 일반 페달을 이용하는 그룹, 조이스틱을 이용하는 3 개의 그룹으로 나누 었다. 3 개의 그룹 간의 전체적인 운전 성능 특성을 비교하 기 위하여 One-way ANOVA 방법을 사용하였다. $p$ 값이 0.05 미만인 경우에 통계학적인 유의성이 있는 것으로 정의 하였다.

\section{Results}

\subsection{Identification of threshold value from bio-signal in subjects}

좌 우 눈흘김 신호에서 제어를 위한 기준값을 설정하기 위 해 실험자의 뇌파 전극캡을 착용 후에 3회 눈을 좌 우로 움 직이는 동작을 힘을 주어 수행한다(Figure 5 (a)). 이 때 발 생하는 신호의 최대값이 실험자가 눈흘김을 통해 낼 수 있는 가장 큰 신호이며 최대 측정값이라 정의한다(Figure 5 (b)). 한편, 눈을 좌우로 정확히 흘겨 보는 것이 아니라 조금 위 또는 아랫방향이 포함된 대각선 방향으로 흘겨보는 경우 신 호는 일반적으로 최대 측정값의 $60 \%$ 를 넘지 못한다. 따라 서, 본 연구에서는 각각의 실험대상자의 반응 기준값을 최대 측정값의 $60 \%$ 로 설정하였다. 


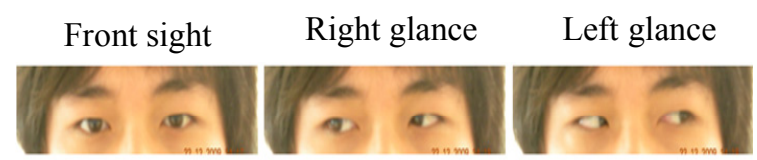

(a) Quick left/right glance

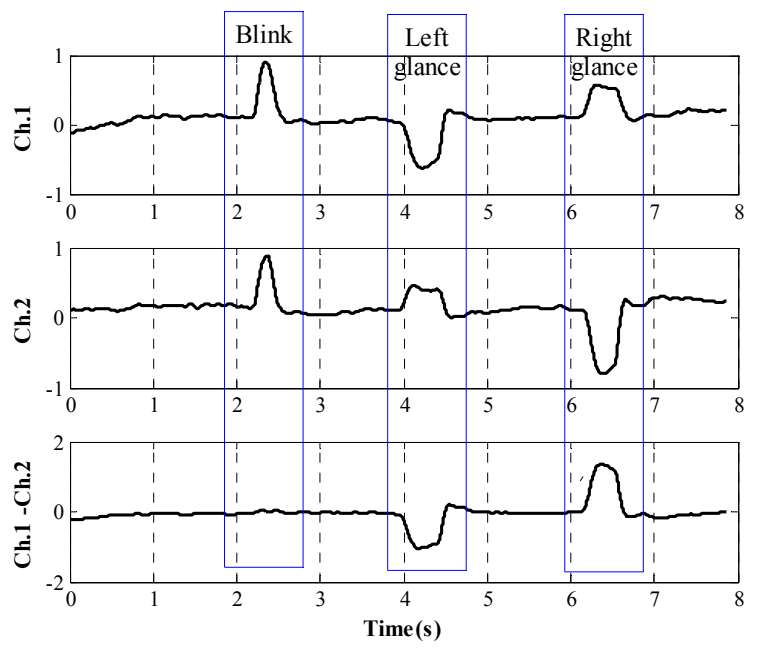

(b) Results from EEG sensors

Figure 5. Results from EEG sensors during quick glance

\subsection{Characteristics of driving performance during test sessions}

개발된 장치를 시뮬레이터 환경에서 성능 평가를 실시하 였다. 생체 신호를 이용하여 가감속을 제어하는 방법의 대조 군으로 조이스틱을 이용한 방법과 페달을 사용한 방법으로 도 성능 평가를 실시하였다. 주행 시험 평가 결과는 먼저 대 상 그룹에 따라서 회차별 점수를 비교하였다(Figure 6). 대다수의 실험대상자는 총 10 회의 주행 시험 중 초기 1,2 차 시기에 교통사고를 내거나, 과속, 핸들조작의 미숙으로 주행 시험 평가에서 불합격 하였다. 기존의 페달을 이용하는 그룹과 생체 신호를 이용하는 그룹의 경우 3 회차부터 합격 선을 유지하는 것으로 나타났다. 하지만 조이스틱을 사용하 는 그룹의 경우 10 번의 실험 중 5 회부터 합격점에 도달하 였다.

\subsection{Comparison of driving performance in three different interface groups}

각 그룹별 평균 점수를 비교한 결과를 Figure 7 에 나타내 었다. 생체 신호를 이용한 그룹이 평균 88.2점으로 가장 높 게 나타났다. 페달을 사용한 그룹은 85.5점, 조이스틱을 사 용한 그룹은 80.9점으로 나타났다. 생체 신호를 이용한 그

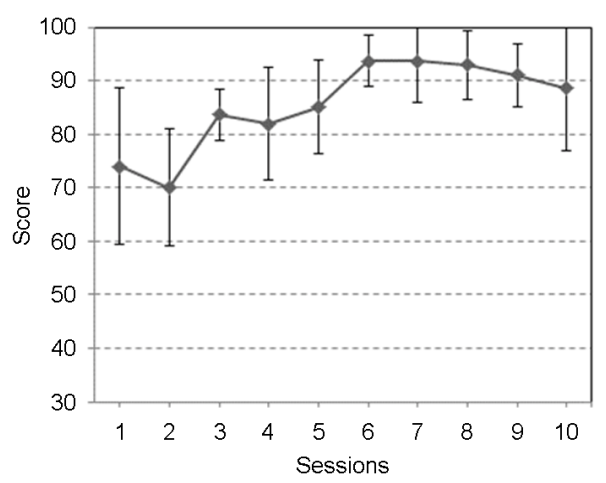

(a) Pedal group

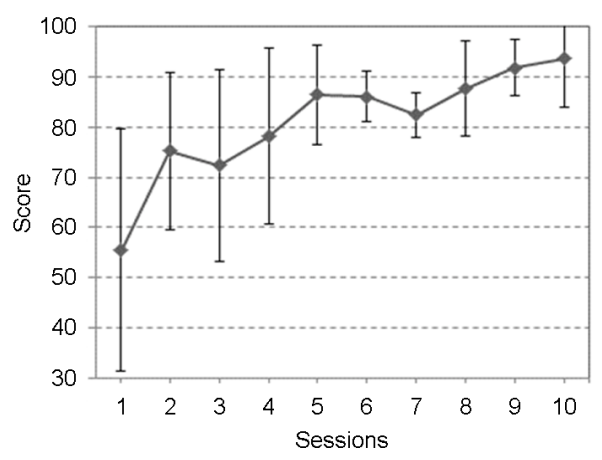

(b) Joystick group

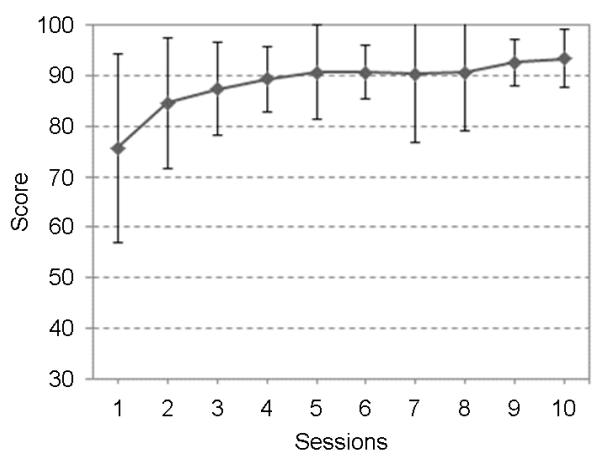

(c) Bio-signal group

Figure 6. Mean driving scores and standard deviations during test sessions

룹이 다른 대조군과 비교했을 때 페달 그룹보다 $3 \%$, 조이스 틱 그룹보다 $9 \%$ 점수가 증가하였으며, One-way ANOVA 분석을 통해서 3 개 그룹에서의 평균값 차이를 분석한 결과 생체 신호를 이용한 가감속 제어 방법이 기존의 페달 그룹이 나 조이스틱 그룹과 비교하여 통계학적으로 유의하게 $(p<$ 0.01) 향상되는 것으로 나타났다. 


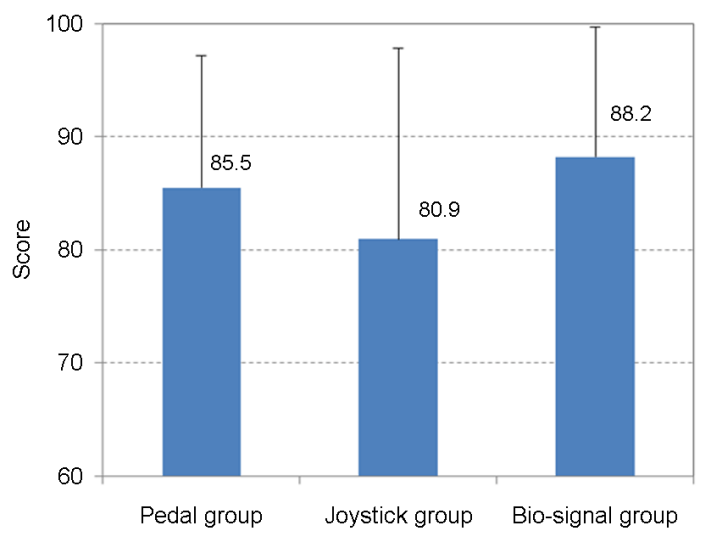

Figure 7. Mean driving scores in three different interface groups

\subsection{Characteristic analysis of driving penalty in different interface groups}

생체 신호를 이용한 가감속 장치에는 속도유지 기능이 있 으므로 조향에 집중할 수 있어 조향 기능의 문제로 인한 감 점 횟수가 대조군과 비교하여 평균 $44 \%$ 감소하였다. 조이 스틱을 사용하는 그룹의 경우 한 손으로 가감속을 제어하고, 다른 한 손으로 조향을 하여야 하기 때문에 조향 기능에 어 려움이 발생하였다. 각 그룹의 조향 기능의 문제로 발생한 감점 횟수는 페달 그룹이 83회, 조이스틱 그룹이 138회였다. 반면, 생체 신호 그룹은 46회로 그 발생률은 페달 그룹에 비 해 $55 \%$, 조이스틱 그룹에 비해 $33 \%$ 로 나왔다(Figure 8).

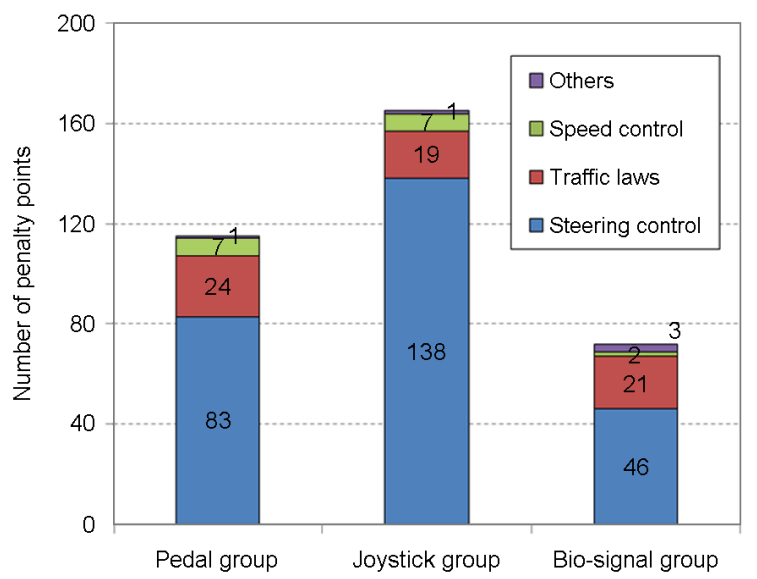

Figure 8. The number of penalty points in three different groups

\section{Conclusion}

본 연구에서 개발한 생체 신호를 이용한 가감속 장치의 성 능 평가 결과 보조 장치를 사용하지 않는 경우(페달 그룹) 와 동일하게 총 10 회중 3 회차부터 합격점에 도달하는 것 으로 나타났다. 또한 전체적인 주행 점수를 고려했을 때 기 존의 페달 그룹이나 조이스틱을 이용한 그룹과 비교해서 각각 $3 \%, 9 \%$ 증가하였으며, 또한 통계학적으로 유의하게 $(p<0.01)$ 증가하는 것으로 나타났다. 특히, 생체 신호를 이 용한 가감속 장치의 경우 속도유지 기능이 있기 때문에 주행 시 감점 횟수가 다른 그룹 보다 $44 \%$ 감소하였다.

본 연구에서 개발된 장치를 사용하여 통제된 환경에서 시 뮬레이터를 사용한 결과 기존의 다른 장치에 비해 주행 성 능이 향상되는 것을 확인하였다. 이는 통제된 환경에서 개발 된 가감속 장치의 사용 가능성을 확인한 것으로, 이것을 바 탕으로 후속연구를 통해서 향후 시뮬레이터가 아닌 자동차 에 적용하는 연구가 이루어진다면, 보다 중증 장애인들이 운 전할 수 있는 기반이 마련될 것으로 생각된다. 이러한 기술 을 통하여 중증 장애인의 이동권이 확보되고 삶의 질을 향 상시키는데 기여할 것으로 사료된다.

\section{Acknowledgements}

This work was supported by the National Research Foundation of Korea(NRF) grant funded by the Korea government(MEST) (No. 2011-0014458).

\section{References}

Barea, R., Boquete, L. and Mazo, M., Lopez, E., System for assisted mobility using eye movements based on electrooculography, IEEE Transactions on Neural System and Rehabilitation Engineering, 10(4), 209-218, 2002.

Employment Development Institute, Survey on the Employment Status of the Disabled in Business, 2010, http://edi.kead.or.kr.

Eoh, H. J., Chung, M. K. and Kim, S-H., Electroencephalographic study of drowsiness in simulated driving with sleep deprivation, International Journal of Industrial Ergonomics, 35(4), 307-320, 2005.

Galan, F., Nuttin, M., Lew, E., Ferrez, P. W., Vanacker, G., Philips, J. and Millan, J. del R., A brain-actuated wheelchair: asynchronous and non-invasive brain-computer interfaces for continuous control of robots, Clinical Neurophysiology, 119(9), 2159-2169, 2008. 
Iturrate, I., Antelis J. M., Kubler, A. and Mingues, J., A noninvasive brainactuated wheelchair based on a P300 neurophysiological protocol and automated navigation, IEEE Transactions on Robotics, 25(3), 614-627, 2009.

Jaime, G-G., Israel, S-J-G., Luis, F. N-A. and Alonso-Garcia Sergio, A-G., Steering a tractor by means of an EMG-based human-machine interface, Sensors, 11, 7110-7126, 2011.

Kim, K-H., Kim, H. K., Kim, J-S., Son, W. and Lee, S-Y., A biosignalbased human interface controlling a power-wheelchair for people with motor disabilities, ETRI Journal, 28(1), 111-114, 2006.

Korea Institute for Health and Social Affairs, Survey of Disability 2005, http://www.kihasa.re.kr.

Kwak, J., Jeon, T., Park, H., Kim, S. and An, K., Development of an EMG-based car interface using artificial neural networks for the physically handicapped, Korea Society of IT Service, 7(2), 149-164, 2008.

Lee, D-Y., Rhee, K-M., Lee, D-Y., Lee, S-C., Lee, S-W., Lim, M-J. and Kim, K-M., A study on the conceptual design of cars accessible for persons with disabilities, The Journal of Special Education: Theory and Practice, 5(3), 139-159, 2004.

Oonishi, Y., Oh, S. and Hori, Y., A new control method for power-assisted wheelchair based on the surface myoelectric signal, IEEE Transactions on Industrial Electronics, 57(9), 3191-3196, 2010.

Park, S-S., Hu, H. and Lee, W-S., A study on physiological signal changes due to distraction in simulated driving, Journal of the Ergonomics Society of Korea, 29(1), 55-59, 2010.

Pellerito, Jr., J. M., Driver rehabilitation and community mobility principle and practice, Elsevier Mosby, USA, 2006.

Rebsamen, B., Teo, C.L., Zeng, Q., Ang Jr., M. H., Burdet, E., Guan, C., Zhang, H. and Laugier, C., Controlling a wheelchair indoors using thought, IEEE Intelligent Systems, 22(2), 18-23, 2007.

Road Traffic Act, Article 54, Section 2 \& Article 61, 2011, http:/law.go.kr.

Road Traffic Authority, Driver's License Examination Office, http:// www.dla.go.kr.

Statics Korea, Survey of Census Population, 2009, http://www.kostat.go.kr.

Tanaka, K., Matsunaga, K. and Wang, H. O., Electroencephalogram-based control of an electric wheelchair, IEEE Transactions on Robotics, 21(4), 762-766, 2005.
Tsutomu, I., Selection of automobiles and assist devices for persons with physical disabilities, National Rehabilitation Center for Persons with Disabilities, Japan, 2004.

Vanacker, G., Millan J. del R., Lew, E., Ferrez, P. W., Galan, F., Philips, J., Brussel, H. V. and Nuttin, M., Context-based filtering for assisted brain-actuated wheelchair driving, Computational Intelligence and Neuroscience, vol.2007, Article ID 25130, 12pages, 2007.

Zhao, Q. B., Zhang, L. Q. and Cichocki, A., EEG-based asynchronous BCI control of a car in 3D virtual reality environments, Chinese Science Bulletin, 54(1), 78-87, 2009.

Zhao, C., Zhao, M., Liu, J. and Zheng, C., Electroencephalogram and electrocardiograph assessment of mental fatigue in a driving simulator, Accident Analysis and Prevention, 45, 83-90, 2012.

\section{Author listings}

Younghyun Kim: swoonyelf@hanmail.net

Highest degree: M.A, Department of Rehabilitation Science and Technology, Daegu University

Areas of interest: Driver Rehabilitation, Rehabilitation Engineering

Yongchul Kim: nakim@daegu.ac.kr

Highest degree: $\mathrm{PhD}$, Department of Mechanical Engineering, POSTECH

Position title: Assistant Professor, Department of Rehabilitation Science \& Technology, Daegu University

Areas of interest: Biomechanics, Rehabilitation Engineering

Date Received : 2011-11-09

Date Revised :2012-02-24

Date Accepted : 2012-02-28 